\title{
Behaviorally Informed Health Policy? Patient Autonomy, Active Choosing, and Paternalism
}

\section{Citation}

Cass R. Sunstein, Behaviorally Informed Health Policy? Patient Autonomy, Active Choosing, and Paternalism, in Nudging Health: Health Law and Behavioral Economics (forthcoming 2015).

\section{Permanent link}

http://nrs.harvard.edu/urn-3:HUL.InstRepos:16162450

\section{Terms of Use}

This article was downloaded from Harvard University's DASH repository, and is made available under the terms and conditions applicable to Other Posted Material, as set forth at http:// nrs.harvard.edu/urn-3:HUL.InstRepos:dash.current.terms-of-use\#LAA

\section{Share Your Story}

The Harvard community has made this article openly available.

Please share how this access benefits you. Submit a story.

\section{Accessibility}


Preliminary draft 12/3/14

All rights reserved

Forthcoming, Nudging Health: Health Law and Behavioral Economics (John

Hopkins University Press 2015)

\title{
Behaviorally Informed Health Policy? Patient Autonomy, Active Choosing, and Paternalism
}

\author{
Cass R. Sunstein*
}

\section{Choices and Default Rules}

Consider the following problems:

1. A private company is deciding among three options: to enroll people automatically in a health insurance plan; to ask them to opt in if they like; or to say that as a condition for starting work, they must indicate whether they want health insurance, and if so, which plan they want.

2. A doctor is deciding whether to suggest a default treatment for a cancer patient or instead to outline a series of options for that patient, to present them in a neutral fashion, and to ask the patient to choose for herself.

3. Having adopted a wellness program, an employer is deciding whether to select an "opt out" design, presuming employee participation (but allowing them to elect not to do so) or instead an "opt in" design -- or alternatively to require employees, in January of every year, to say whether they want to participate.

In these cases, and countless others, an institution is deciding whether to use some kind of default rule or instead to require some kind of active choice. For those who reject paternalism and who prize freedom of choice, active choosing has evident appeal, perhaps especially in the domain of health care. Indeed active choosing might seem far

\footnotetext{
* Robert Walmsley University Professor, Harvard University. I am grateful to Glenn Cohen, Elizabeth Emens, Eric Johnson, George Loewenstein, Eric Posner, Riccardo Rebonato, Lucia Reisch, and Adrian Vermeule for valuable comments on a previous draft. Special thanks to participants in a conference at Harvard Law School, where this essay was initially presented. I am also grateful to participants in a legal theory workshop at Yale Law School and to audiences at Dartmouth College for excellent suggestions and to Matthew Lipka for superb comments and research assistance. Much of the material here draws on an earlier discussion in Cass R. Sunstein, Choosing Not to Choose (forthcoming, Oxford University Press, 2015) and Choosing Not To Choose, 64 Duke LJ 1 (2014), available at http://papers.ssrn.com/sol3/papers.cfm?abstract id $=2377364$; the goal of this chapter is to present a simple, self-contained version of a central argument in those longer works and to focus the question on matters of health.
} 
preferable to any kind of default rule. Hospitals and doctors frequently think so, emphasizing the idea of "patient autonomy" - an idea that can be connected with the central argument in John Stuart Mill's great essay, On Liberty.

In recent years, there have been vigorous debates about freedom of choice, paternalism, behavioral economics, individual autonomy, and the use of defaults. Invoking recent behavioral findings, some people have argued that because human beings err in predictable ways, and cause serious problems for themselves, some kind of paternalism is newly justified, especially if it preserves freedom of choice, as captured in the idea of "libertarian paternalism.", These arguments have evident applications to health-related policies of many kinds. Others contend that because of those very errors, some form of coercion is required to promote people's welfare, and that the argument for choice-denying or nonlibertarian paternalism is much strengthened. ${ }^{3}$ These claims raise special problems in the area of health and health care, whether the question involves food safety, insurance plans, the design of wellness programs, or the relationship between doctors and patients.

A possible concern is that those who oversee or provide health care are prone to error as well, and hence an understanding of behavioral biases argues against paternalism, not in favor of it. ${ }^{4}$ In particular, the "knowledge problem" potentially affects all decisions by government, including officials who are involved in health care, and behavioral findings seem to compound that problem, because they suggest that identifiable biases will accompany sheer ignorance. Hospitals, insurance providers, and doctors can fall prey to the knowledge problem as well. Because patients have superior knowledge of their own values, tastes, and situations, the knowledge problem might well argue for active choosing.

It might also be objected that on grounds of both welfare and autonomy, active choosing is desirable even if people have a tendency to err. ${ }^{6}$ On this view, people (emphatically including patients) should be asked or allowed to choose, whether or not they would choose rightly - not least when their health and well-being are on the line. For all sides, the opposition between paternalism and active choosing seems stark and

\footnotetext{
${ }^{1}$ See, e.g., SARAh CONly, Against Autonomy (2012); Richard H. Thaler \& CASS R. Sunstein, Nudge: Improving Decisions About Wealth, Health, and Happiness (2008); Ryan Bubb \& Richard Pildes, How Behavioral Economics Trims Its Sails and Why, 127 HARV. L. REV. (forthcoming 2014); Colin Camerer et al., Regulation for Conservatives: Behavioral Economics and the Case for Asymmetric Paternalism, 151 U. PA. L. REV. 1211 (2003); Joshua D. Wright \& Douglas H. Ginsburg, Behavioral Law and Economics: Its Origins, Fatal Flaws, and Implications for Liberty, 106 Nw. U.L. REV. 1033 (2012); Riccardo Rebonato, A Critical Assessment of Libertarian Paternalism (2012), available at http://papers.ssrn.com/sol3/papers.cfm?abstract_id=2346212.

${ }^{2}$ See Camerer et al., supra note; Cass R. Sunstein \& Richard H. Thaler, Libertarian Paternalism Is Not An Oxymoron, 70 U. CHI. L. REV. 1159 (2003).

${ }^{3}$ See CONLY, supra note; Bubb and Pildes, supra note.

${ }^{4}$ See Edward Glaeser, Paternalism and Psychology, 73 U. CHI. L. REV. 133 (2006).

${ }^{5}$ Friedrich Hayek, The Uses of Knowledge in Society, 35 Am. Econ. Rev. 519 (1945).

${ }^{6}$ See Wright and Ginsburg, supra note.
} 
plain, and indeed it helps to define all of the existing divisions. Some insurance providers, and some hospitals and doctors, seem to insist on the opposition.

My central goal here is to unsettle that opposition and to suggest that it is often illusory. In many contexts, an insistence on active choosing is a form of paternalism, not an alternative to it. This is emphatically true in the context of health care. The central reason is that some people choose not to choose. ${ }^{7}$ Sometimes they make that choice explicitly (and indeed are willing to pay a considerable amount to people who will choose for them). They have actively chosen not to choose.

Sometimes people (including some patients) have made no explicit choice; they have not actively chosen anything. But it is nonetheless reasonable to infer that in particular contexts, their preference is not to choose, and they would say so if they were asked. They might fear that they will err. They might be aware of their own lack of information $^{8}$ or perhaps their own behavioral biases (such as unrealistic optimism"). They might find the underlying questions confusing, difficult, painful, and troublesome -- empirically, morally, or otherwise. They might not enjoy choosing. They might be busy and lack "bandwidth." 10 They might not want to take responsibility for potentially bad outcomes for themselves (and at least indirectly for others). ${ }^{11}$ They might anticipate their own regret and seek to avoid it. ${ }^{12}$ In the medical context, patients might be under considerable stress, and prefer some kind of default rule, or strong suggestion, for exactly that reason.

\footnotetext{
${ }^{7}$ An important clarification: My focus throughout is not on "not choosing," which involves no choice at all, and which is different from choosing not to choose, in the sense of choosing someone else to choose on one's behalf. One might not choose because (for example) of procrastination or because one wants to retain option value. See Ziv Carmon et al., Option Attachment: When Deliberating Makes Choosing Feel Like Losing, 30 J. CONST. RES. 15 (2003). There is, of course, an overlap between the two phenomena: People might decline to choose because they are busy, do not want to take responsibility, or think that they might err. But choosing not to choose is a form of choice, and those who want to avoid choosing might be as adverse to that choice as any other.

${ }^{8}$ On the effects of lack of information in producing abstention, see Tom Coupe \& Abdul Noury, Choosing Not to Choose: On the Link Between Information and Abstention, 84 ECON. LETTERS 261 (2004).

${ }^{9}$ See TAli Sharot, The Optimism Bias: A TOUR of the Irrationally Positive Brain (2011).

${ }^{10}$ See SENDhil Mullainathan \& Eldar SHAFIR, SCARCity 39-66 (2013).

${ }^{11}$ For a demonstration, see Bjorn Bartling \& Urs Fischbacher, Shifting the Blame: On Delegation and Responsibility, 79 REV. ECON. STUD. 67 (2012). On people's preference for flipping a coin, as a way of avoiding responsibility, see Nadja Dwengler et al., Flipping A Coin: Theory and Evidence (2013) (unpublished manuscript). Consider this suggestion, $i d$. at 1: The "cognitive or emotional cost of deciding may outweigh the benefits that arise from making the optimal choice. For example, the decision-maker may prefer not to make a choice without having sufficient time and energy to think it through. Or, she may not feel entitled to make it. Or, she may anticipate a possible disappointment about her choice that can arise after a subsequent resolution of uncertainty. Waiving some or all of the decision right may seem desirable in such circumstances even though it typically increases the chance of a suboptimal outcome."

${ }^{12}$ Richard Thaler, Toward a Positive Theory of Consumer Choice, 1 J. ECON. BEHAV. \& ORG. 39, 51-54 (1980).
} 
But even when people prefer not to choose, many private and public institutions favor and promote active choosing on the ground that it is good for people to choose. To this extent, active choosing counts as paternalistic. Choice-requiring paternalism might be an attractive form of paternalism, but it is no oxymoron, and it is paternalistic nonetheless. That form of paternalism is particularly common in the medical context. In a sense, it overrides patient autonomy, though it purports to operate in the name of that ideal.

If people are required to choose even when they would prefer not to do so, active choosing counts as a species of non-libertarian paternalism in the sense that people's own choice not to choose is being rejected. We shall see that in many cases, those who favor active choosing (including doctors and health insurers) are actually mandating it, and may therefore be overriding (on paternalistic grounds) people's choice not to choose. ${ }^{13}$ When people prefer not to choose, required choosing is a form of coercion though it may be the right form, at least where active choosing does not increase the likelihood and magnitude of errors, and where it is important to enable people to learn and to develop their own preferences.

If, by contrast, people are asked whether they want to choose, and can opt out of active choosing (in favor of, say, a default rule), active choosing counts as a form of libertarian paternalism. In some cases, it is an especially attractive form. A doctor might ask people whether they want to make a choice among treatments, or instead rely on the standard approach. A company might ask people whether they want to choose the privacy settings on their computer, or instead rely on the default, or whether they want to choose their electricity supplier, or instead rely on the default.

With such an approach, people are being asked to make an active choice between the default and their own preference, and in that sense, their liberty is fully preserved. Call this simplified active choosing. Simplified active choosing has the advantage of avoiding the kinds of pressure that come from a default rule, ${ }^{14}$ while also allowing people to rely on such a rule if they like. In the future, we should see, and we should hope to see, adoption of this approach by a large number of institutions, both public and private, and it has strong claims for adoption in the medical domain.

The remainder of this chapter is organized as follows. Part II explores how, and in what settings, active choosing might be required. Part III draws attention to choicerequiring paternalism and shows that it is not a contradiction in terms. It explains that when people choose not to choose, active choosing counts as a form of paternalism, one that runs into both welfare-based and autonomy-based arguments in favor of freedom of choice (including the choice not to choose). This point holds even for simplified active

\footnotetext{
${ }^{13}$ There is an irony here in light of evidence that people sometimes place an excessive value on choice, in the sense that their preference for choice leads to welfare losses. See Simona Botti \& Christopher Hsee, Dazed and Confused by Choice, 112 Org. Behav. ANd Hum. DeCision Processes 161 (2010).

${ }^{14}$ See Eric J. Johnson \& Daniel G. Goldstein, Decisions by Default, in The Behavioral Foundations of POLICY 417, 417-18 (Eldar Shafir ed., 2013) (discussing impact of defaults).
} 
choosing, though the standard objections to paternalism are weakened as applied to that approach. Part IV concludes.

\section{Serving Health? Varieties of Choice}

Many of those who embrace active choosing believe that consumers of goods and services, and indeed choosers of all sorts (including patients), should be free from government influence, or perhaps from the influence of private institutions of all kinds. ${ }^{15}$ Of course they recognize that in markets, producers will impose influences of multiple kinds, but they contend that when third parties are not affected, and when force and fraud are not involved, government should remain neutral. They reject paternalism. ${ }^{16}$ Perhaps it is legitimate to provide accurate information, so as to ensure that people's choices are adequately informed. But if public officials, hospitals, or doctors seek to "nudge" people in its preferred directions in other ways - by imposing default rules or embracing paternalism of any kind - it is exceeding its appropriate bounds.

\section{A. Three Possibilities}

But what does active choosing entail? ${ }^{18}$ What does it mean to "require" people to indicate their preferences? What does it mean for the health care system to do so? Those who insist on the inevitability of default rules will object that there is no good answer to this question. Even if choice architects seek to promote active choosing, they have to specify what happens if people simply refuse to choose. Isn't the answer some kind of default rule?

The question is a good one, because some kind of default rule is ultimately necessary. Choice architects have to establish what happens if people decline to choose. But this point should not be taken to collapse the distinction between active choosing and default rules. To see why, consider three possibilities.

(a) Criminal or civil punishment for those who refuse to make an active choice. In most contexts, no one contends that if people fail to make a choice, they should be imprisoned or otherwise punished. The sanction for that failure is that they do not receive a good or service (see (b) and (c) below). But there are exceptions. In some nations, including Australia,

\footnotetext{
${ }^{15}$ This is the general thrust of Rebonato, supra note.

${ }^{16}$ Id.; Wright \& Ginsburg, supra note.

${ }^{17}$ See THALER \& SUNSTEIN, supra note.

${ }^{18} \mathrm{I}$ am understanding the term in a purely formal sense, to capture a response to a question about what one prefers. It would be possible to understand "choosing" in a more functional sense, to capture deciding for reasons, as distinguishing from simply "picking," which is akin to tossing a coin. For an important discussion, see Edna Ullmann-Margalit \& Sidney Morgenbesser, Picking and Choosing, 44 SoCIAL RESEARCH 757 (1977). As I understand it here, active choosing includes "picking," and can occur even when people lack an antecedent preference.
} 
Belgium, and (before 1970) the Netherlands, people have been subject to civil sanctions if they fail to vote, ${ }^{19}$ and in that sense they may be punished for refusing to make an active choice. So too, the Affordable Care Act requires people to make a choice about health insurance, subject to punishment if they fail to do so. ${ }^{20}$

With respect to active choosing, both of these cases do have a wrinkle: People are being forced to choose along one dimension (for whom to vote and which health insurance plan to obtain), but are being prohibited from choosing along another dimension (whether to vote or to obtain health insurance). But insofar as one kind of choice is being required, we may fairly speak of coerced choosing.

We could imagine other contexts in which people would face sanctions if they do not choose, though admittedly such cases look more like science fiction than the real world. Consider cases in which people must decide whether to become organ donors (or face criminal penalties) or must choose privacy settings on their computer (subject to civil sanctions if they do not). The fact that sanctions are rarely imposed on people who choose not to choose (including in the medical context) might be taken to suggest an implicit recognition that in a free society, such choices are generally acceptable and indeed a legitimate part of consumer sovereignty. One reason involves information: People know best what they want, and others should not choose for them, even if the choice is not to choose. ${ }^{21}$ The question is whether this point holds in the particular context.

(b) Active choosing with respect to a related or ancillary matter as a condition for obtaining a good or a service (or a job). Sometimes active choosing is mandatory in a distinctive sense: Unless people make an active choice on some matter, they cannot obtain a good or service, even though that good or service, narrowly defined, is not the specific topic of the choice that they are being asked to make. We can imagine a continuum of connections between the matter in question, for which an active choice is being required, and the specific good that has already been chosen. There would be a fairly close connection if, for example, people were told that unless they indicate their preferences with respect to health insurance, they cannot start work. So too, there would be a close connection if people were told that unless they create a password, or indicate their preferences with

\footnotetext{
${ }^{19}$ Lisa Hill, Low Voter Turnout in the United States: Is Compulsory Voting A Solution, 18 J. THEORETICAL POL. 207, 208 (2006).

${ }^{20} 26$ U.S.C. $§ 5000$ A (2012). Note that by 2015, large employers will be required to adopt a form of automatic enrollment for health insurance. See 29 U.S.C. 218A.

${ }^{21}$ For a powerful demonstration, see Joel Waldfogel, SCROOGENOMICS: Why You SHOULDN'T BuY PRESENTS FOR THE HOLIDAYS (2009) (showing that even family members and close friends make large mistakes in choosing for people during holiday season).
} 
respect to privacy settings, they cannot use their computer. And indeed, both of these cases are standard.

By contrast, there would be a weaker connection if people were told that they could not obtain a drivers' license unless they indicate their preferences with respect to organ donation. The connection would be even weaker if people were told that they could not register to vote unless they have made a choice about their preferred privacy settings on their computer.

In the final two examples, there is not a tight connection between the matter on which people are being asked to make a choice and the good that they are specifically seeking. ${ }^{22}$ In some cases, the choice architect is requiring an active choice on a matter that is genuinely ancillary. Note that in imaginable cases that fall in this category, the requirement of active choosing has a strongly coercive dimension insofar as the good in question is one that people cannot easily reject (such as a driver's license, a job, or a right to vote). The choice architect is, in effect, leveraging that good to ensure an active choice on some other matter.

(c) Active choosing among goods, services, or jobs as a condition for obtaining a good, a service, or a job. For most consumption decisions, people are given a range of options, and they can choose one or more of them, or none at all. Unless they make a choice, they will not obtain the relevant good or service. When people visit a website, a restaurant, or a grocery or appliance store, they are generally asked to make an active choice. The default - understood as what happens if they do nothing - is that no product will be purchased. People do not receive goods or services unless they have actively chosen them. The same point holds for the employment market. People are not typically defaulted into particular jobs, at least not in any formal sense. They have a range of options, and unless they take one, they will be unemployed. In this respect, free markets generally require active choosing.

There is nothing inevitable about this situation. We could imagine a situation in which sellers assume, or presume, that people want certain products, and in which buyers obtain them, and have to pay for them, passively. Suppose, for example, that an employer has sufficient information to know that Johnson would do best with a particular health insurance plan - and defaults Johnson into that system accordingly (subject to personal adjustments). Indeed, that approach is hardly uncommon. One

\footnotetext{
${ }^{22}$ There is a counterargument in the case of organ donations. In 2007, for example, motor vehicle accidents accounted for about 20 percent of all organ donations. See Stacy Dickert-Conlin et al., Donorcycles: Motorcycle Helmet Laws and the Supply of Organ Donors, 54 J.L. \& Econ. 907, 912 (2011).
} 
reason is that Johnson may not have a great deal of expertise about which plan is best - and hence a default is very much in his interest.

\section{B. Choice Architects: Insurers, Hospitals, Doctors, and Beyond}

As the examples suggest, both private and public institutions might choose (b) or (c), though of course only government can choose (a). It should be clear that active choosing is far from inevitable. Instead of imposing active choosing, an institution (including a health insurer or a hospital) might select some kind of default rule, specifying what happens if people do nothing. Of course (b) and (c) also come with a kind of default rule: unless people make an active choice, they will have no good, no service, and no employment. But other approaches are possible.

For example, those who obtain driver's licenses might be defaulted into being organ donors, or those who start work with a particular employer might be defaulted into a health care plan. Alternatively, those who make an active choice to purchase a particular product - say, a book or a subscription to a magazine - might be enrolled into a program by which they continue to receive a similar product on a periodic basis, whether or not they have not made an active choice to do that. The Book of the Month Club famously employs a strategy of this sort. ${ }^{23}$

To take an example far from the medical context: Suppose, for example, that a private institution knows that people who purchase product X (say, certain kinds of music) also tend to like product Y (say, certain kinds of books). Suggestions of various kinds, default advertisements, default presentations of political views, and perhaps even default purchases could be welcome and in people's interests, unfamiliar though the link might seem. For example, the website Pandora tracks people's music preferences, from which it can make some inferences about likely tastes and judgments about other matters, including politics. ${ }^{24}$

We could also imagine cases in which people are explicitly asked to choose whether they want to choose. ${ }^{25}$ Patients might be asked: Do you want to make a series of choices, or do you want to be defaulted into those that seem to work best for most people, or for people like you? Do you want to choose your own health insurance plan,

\footnotetext{
${ }^{23}$ See Peter Bowal, Reluctance to Regulate: The Case of Negative Option Marketing, 36 AM. BUS. L.J. 377, 378-79 (1999).

${ }^{24}$ For evidence to this effect, see Natasha Singer, Listen to Pandora, and It Listens Back, N.Y. TIMES, Jan. 5, 2014, at BU3, available at http://www.nytimes.com/2014/01/05/technology/pandora-mines-users-datato-better-target-ads.html?hpw\&rref=technology\&_r=2\&, and consider in particular: "During the next federal election cycle, for instance, Pandora users tuning into country music acts, stand-up comedians or Christian bands might hear or see ads for Republican candidates for Congress. Others listening to hip-hop tunes, or to classical acts like the Berlin Philharmonic, might hear ads for Democrats." Id.

${ }^{25}$ See Bartling et al., supra note, which shows that people will often say "yes," other things being equal, thus supporting the conclusion that decision rights have intrinsic value. We can agree with that conclusion while also asserting that in some cases, the intrinsic value will be outweighed by the instrumental value of delegation (as, for example, where people believe they will err, or where people are busy).
} 
or do you want to be defaulted into the plan that seems best for people in your demographic category? In such cases, many people may well decide in favor of a default rule, and thus decline to choose, because of a second-order desire not to do so. They might not trust their own judgment; they might not want to learn. The topic might make them anxious. They might have better things to do. They might want to appoint some kind of surrogate, or to allow for such an appointment.

Simplified active choosing - active choosing, with the option of using a default -has considerable promise and appeal, not least because it avoids at least many of the influences contained in a default rule, ${ }^{26}$ and might therefore seem highly respectful of autonomy while also giving people the ability to select the default. For cell phone settings or health insurance plans, active choosers can choose actively if they like, while others can (actively) choose the default.

Note, however, that this kind of question is not quite a perfect solution, at least for those people who genuinely do not want to choose. After all, they are being asked to do exactly that. At least some of those people (including some patients) likely do not want to have to choose between active choosing and a default rule, and hence they would prefer a default rule to an active choice between active choosing and a default rule. Even that active choice takes time and effort, and imposes costs, and some or many people might not want to bother. In this respect, supposedly libertarian paternalism, in the form of an active choice between active choosing and a default, itself has a strong nonlibertarian dimension - a conclusion that brings us directly to the next section.

\section{Choice-Requiring Paternalism}

\section{A. Paternalism, Welfare, Autonomy}

Is it paternalistic to require active choosing, when people (for example, employees or patients) would prefer not to choose? Is it paternalistic for health insurers and doctors to require people to choose?

To answer these questions, we have to start by defining paternalism. There is of course an immensely large literature on that question. ${ }^{27}$ Let us bracket the hardest questions and note that while diverse definitions have been given, it seems clear that the unifying theme of paternalistic approaches is that a private or public institution does not believe that people's choices will promote their welfare, and it is taking steps to influence or alter people's choices for their own good. ${ }^{28}$

\footnotetext{
${ }^{26}$ See Rebonato, supra note.

${ }^{27}$ See, e.g., PATERnAlism (Christian Coons \& Michael Weber eds., 2013); GERALD DWORKIN, The TheORY AND PRACTICE OF AUTONOMY (1988).

${ }^{28}$ For a valuable and relevant discussion, bearing particularly on means paternalism, see B. Douglas Bernheim \& Antonio Rangel, Beyond Revealed Preference: Choice Theoretic Foundations for Behavioral Welfare Economics, 124 Q.J. ECON. 51 (2009).
} 
What is wrong with paternalism, thus defined? Those who reject paternalism typically invoke welfare, autonomy, or both. ${ }^{29}$ They tend to believe that individuals are the best judges of what is in their interests, and of what would promote their welfare, and that outsiders should decline to intervene because they lack crucial information. ${ }^{30}$ John Stuart Mill himself emphasized that this is the essential problem with outsiders, including government officials. Mill insisted that the individual "is the person most interested in his own well-being," "and the "ordinary man or woman has means of knowledge immeasurably surpassing those that can be possessed by any one else." ${ }^{, 32}$ When society seeks to overrule the individual's judgment, it does so on the basis of "general presumptions," and these "may be altogether wrong, and even if right, are as likely as not to be misapplied to individual cases." ${ }^{33}$ Mill's goal was to ensure that people's lives go well, and he contended that the best solution is for public officials to allow people to find their own path. ${ }^{34}$

This is an argument about welfare, grounded in a claim about the superior information held by individuals. It very much applies to patients, who have unique access to their own tastes, values, fears, hopes, and situations. But there is an independent argument from autonomy, ${ }^{35}$ which emphasizes that even if people do not know what is best for them, and even if they would choose poorly, they are entitled to do as they see fit (at least so long as harm to others, or some kind of collective action problem, is not involved). On this view, freedom of choice has intrinsic and not merely instrumental value. It is an insult to individual dignity, and a form of infantilization, to eliminate people's ability to go their own way. ${ }^{36}$ The interest in patient autonomy stems in part from an insistence on this point.

\section{B. Choice-Requiring Paternalism}

Whether or not these objections to paternalism are convincing, ${ }^{37}$ there are legitimate questions about whether and how they apply to people whose choice is not to choose. On reflection, they apply quite well, and so choice-requiring paternalism is no oxymoron. People might decline to choose for multiple reasons. They might believe that they lack information or expertise. They might fear that they will err. They might not enjoy the act of choosing; they might like it better if someone else decides for them. They might not want to incur the emotional costs of choosing, especially for situations that are painful or

${ }^{29}$ Rebonato, supra note, is an especially helpful discussion.

${ }^{30}$ FRIEDRICH HAYEK, THE MARKET AND OTHER ORDERS 384-86 (Bruce Caldwell ed., 2014).

${ }^{31}$ John Stuart Mill, On Liberty (Kathy Casey ed., 2002) (1859).

${ }^{32} I d$.

${ }^{33} I d$.

${ }^{34}$ See also HAYEK, supra note.

${ }^{35}$ For a recent version, see Wright \& Ginsburg, supra note.

${ }^{36}$ For an illuminating and skeptical discussion, suggesting that overriding choices need not entail a lack of respect, see CONLY, supra note.

${ }^{37}$ For detailed discussion, see id.; CASs R. Sunstein, Why Nudge? The Politics of Libertarian PATERNALISM (2014). 
difficult to contemplate (such as organ donation or end-of-life care). They might find it a relief, $^{38}$ and in some contexts even fun, to delegate. They might not want to take responsibility. ${ }^{39}$ They might be too busy. ${ }^{40}$ They might not want to pay the psychic costs associated with regretting their choice. ${ }^{41}$ Active choosing saddles the chooser with responsibility for the choice, and reduces the chooser's welfare for that reason. This poin emphatically holds in the medical context.

In daily life, people defer to others, including friends and family members, on countless matters, and they are often better off as a result. In ordinary relationships, people benefit from the functional equivalent of default rules, some explicitly articulated, others not. Within a marriage, for example, certain decisions (such as managing finances or planning vacations) might be made by the husband or wife by default, subject to optout in particular circumstances. That practice has close analogues in many contexts in which people are dealing with private or public institutions (including hospitals and doctors) and choose not to choose. Indeed, people are often willing to pay others a great deal to make their choices for them. But even when there is no explicit payment or grant of the power of agency, people might well prefer a situation in which they are relieved of the obligation to choose, because such relief will reduce decision costs, error costs, or both.

Suppose, for example, that Jones believes that he is not likely to make a good choice about his health care plan, and that he would therefore prefer a default rule, chosen by someone who is a specialist in the subject at hand. In Mill's terms: Doesn't Jones know best? Or suppose that Smith is exceedingly busy, and wants to focus on her most important concerns, not on a question about the right health insurance plan for her, or even about the right privacy setting on her computer. Doesn't Mill's argument support respect for Smith's choice? In such cases, the welfarist arguments seem to argue in favor of deference to the chooser's choice, even if that choice is not to choose. If we believe in freedom of choice on the ground that people are uniquely situated to know what is best for them, ${ }^{42}$ then that very argument should support respect for people when they freely choose not to choose.

Or suppose that Winston, exercising his or her autonomy, decides to delegate decisionmaking authority to someone else, and thus to relinquish the power to choose, in a context that involves health insurance, medical care, privacy, or credit card plans. Is it an insult to Winston's dignity, or instead a way of honoring it, if a private or public institution refuses to respect that choice? It is at least plausible to suppose that respect for

\footnotetext{
${ }^{38}$ For related discussion, see Edna Ulmann-Margalit, On Not Wanting to Know, in REASONING PRACTICALLY (Edna Ullmann-Margalit ed.,2000).

${ }^{39}$ See Dwengler et al., supra note, for an emphasis on delegation to a randomized process.

${ }^{40}$ See Mullainathan \& SHAFIR, supra note.

${ }^{41}$ Thaler, supra note. But see Jeffrey R. Brown et al., The Downside of Defaults (Nat'l Bureau Econ. Res. Working Paper No. 12-05, 2012), available at http://www.nber.org/aging/rrc/papers/onb12-05.pdf (finding higher levels of regret in cases in which people went with a default rather than making an active choice).

${ }^{42}$ See HAYEK, supra note.
} 
autonomy requires respect for people's decisions about whether and when to choose. That view seems especially reasonable in view of the fact that people are in a position to make countless decisions, and they might well decide that they would like to exercise their autonomy by focusing on their foremost concerns, not on what seems trivial, boring, or difficult. ${ }^{43}$

But are people genuinely bothered by the existence of default rules, or would they be bothered if they were made aware that such rules had been chosen for them? We do not have a full answer to this question; the setting, and the level of trust, undoubtedly matter. But note in this regard the empirical finding, in the context of end-of-life care, that even when they are explicitly informed that a default rule is in place, and that it has been chosen because it affects people's decisions, there is essentially no effect on what people do. Here is the particular instruction:

The specific focus of this research is on 'defaults' -- decisions that go into effect if people don't take actions to do something different. Participants in this research project have been divided into two experimental groups.

If you have been assigned to one group, the Advance Directive you complete will have answers to questions checked that will direct health care providers to help relieve pain and suffering even it means not living as long. If you want to choose different options, you will be asked to check off different option and place your initials beside the different option you select.

If you have been assigned to the other group, the Advance Directive you complete will have answers to questions checked that will direct health care providers to prolong your life as much as possible, even if it means you may experience greater pain and suffering.

When given this instruction, people are not less likely to follow the particular default. Here, then, is a finding, at least in the context of end-of-life care, that people are not uncomfortable with defaults, even when they are made aware that choice architects have selected them. ${ }^{44}$

\section{Alienating Freedom?}

To be sure, we could imagine hard cases in which a choice not to choose seems to be an alienation of freedom. In the extreme case, people might choose to be slaves or otherwise to relinquish their liberty in some fundamental way. ${ }^{45}$ In a less extreme case, people might choose not to vote, not in the sense of failing to show up at the polls, but in

${ }^{43}$ See Esther Duflo, Tanner Lectures on Human Values and the Design of the Fight Against Poverty (May 2, 2012), http://economics.mit.edu/files/7904.

${ }^{44}$ See George Loewenstein et al., Warning: You Are About To Be Nudged (2014) (unpublished manuscript).

${ }^{45}$ For an overview, see Andrew Sneddon, What's Wrong with Selling Yourself Into Slavery? Paternalism and Deep Autonomy, 73 CRítica Revista HiSPanOAMERICANA DE Filosofia 97 (2001). 
the sense of (formally) delegating their vote to others. Such delegations are impermissible, ${ }^{46}$ perhaps because they would undo the internal logic of a system of voting (in part by creating a collective action problem that a prohibition on vote-selling solves ${ }^{47}$ ), but perhaps also because individuals would be relinquishing their own freedom. Or perhaps people might choose not to make choices with respect to their religious convictions, or their future spouse, ${ }^{48}$ and they might delegate those choices to others. In cases that involve central features of people's lives, we might conclude that freedom of choice cannot be alienated and that the relevant decisions must be made by the individuals themselves.

It is a complex question which cases fall in this category. ${ }^{49}$ But even if the category is fairly large, it cannot easily to taken as a general objection to the proposition that on autonomy grounds, people should be allowed not to choose in multiple domains. Health care can be understood as a context in which we generally do respect choices not to choose, at least in the sense that patients frequently defer to doctors, even or perhaps especially when the stakes are high.

\section{Justified Paternalism?}

It is important to acknowledge that the choice not to choose may not be in the chooser's interest (as the chooser would define it). For that reason, choice-requiring paternalism might have a justification in terms of the chooser's welfare. Perhaps the chooser chooses not to choose only because he lacks important information (which would reveal that the default rule might be harmful) or suffers from some form of bounded rationality. A behavioral market failure (understood as a nonstandard market failure that comes from human error ${ }^{50}$ ) might infect a choice not to choose, just as it might infect a choice about what to choose.

A non-chooser (including a patient) might, for example, be unduly affected by "availability bias" because of an overreaction to a recent situation in which his own choice went wrong. ${ }^{51}$ Or perhaps the chooser is myopic and is excessively influenced by the short-term costs of choosing, which might require some learning (and hence some investment), while underestimating the long-term benefits, which might be very large. A form of "present bias" might infect the decision not to choose. People might face a kind

\footnotetext{
${ }^{46}$ See Steven Rieber, Vote-Selling and Self-Interested Voting, 15 PUB. AFF. Q. 35 (2001).

${ }^{47}$ The basic idea is that if vote-selling were permitted, voting power could be concentrated in individuals or individual entitles, and while decisions to sell might be individually rational, the result would be bad from the standpoint of a large group of vote-sellers. See id.

${ }^{48}$ For relevant discussion, see Amitrajeet Batabyal, On the Likelihood of Finding the Right Partner in an Arranged Marriage, 30 J. Socio-ECON. 273 (2001); Conly, supra note.

${ }^{49}$ CONLY, supra note.

${ }^{50}$ See BAR-GILl, supra note; SunsteIn, Why NudGE?, supra note.

${ }^{51}$ A good overview is Rolf ReBER, Availability, in COGNITIVE ILlusions 147 (Rudiger F. Pohl ed., 2012).

${ }^{52}$ For a summary, see SUNSTEIN, supra note.
} 
of intrapersonal collective action problem, in which such a decision by Jones, at Time 1, turns out to be welfare-reducing for Jones at Times 2, 3, 4, and 5.

But for those who reject paternalism, these kinds of concerns are usually a justification for providing more and better information - not for blocking people's choices, including their choices not to choose. In these respects, the welfarist objections to paternalism seem to apply as well to those who insist on active choosing. Of course welfarists might be wrong to object to paternalism. ${ }^{53}$ But with respect to their objections, the question is whether the choice not to choose is, in general or in particular contexts, likely to go wrong, and in the abstract, there is no reason to think that that particular choice would be especially error-prone. In light of people's tendency to overconfidence, the choice not to choose might even be peculiarly likely to be right, which would create serious problems for choice-requiring paternalism. ${ }^{54}$ In the medical context, we lack evidence that the choice not to choose will go wrong - and in view of the fact that patients often lack information or under stress, the choice to choose might itself result in mistakes (acknowledging that people's tastes, values, and situations greatly matter, which strongly argues in favor of retaining freedom of choice, whether or not it is exercised)

Consider in this regard evidence that people spend too much time trying to make precisely the right choice, in a way that leads to significant welfare losses. In many situations, people underestimate the temporal costs of choosing, and exaggerate the benefits, producing "systematic mistakes in predicting the effect of having more, vs. less, choice freedom on task performance and task-induced affect." ${ }^{, 55}$ If people make such systematic mistakes, it stands to reason that they might well choose to choose in circumstances in which they ought not to do so on welfare grounds. We can easily imagine analogies in the medical context.

My aim is not to endorse the welfarist rejection of paternalism; it is only to say that the underlying arguments apply to all forms of paternalism, including those that would interfere with the decision not to choose. To be sure, some welfarists are willing to interfere with people's choices; they may well be libertarian or nonlibertarian paternalists. ${ }^{56}$ The central points are that the standard welfarist arguments on behalf of freedom of choice apply to those who (freely) choose not to choose, and that those who want to interfere with such choices might well be paternalists. And from the standpoint of autonomy, interference with the choice not to choose seems objectionable as well, unless it is fairly urged that that choice counts as some kind of alienation of freedom.

\section{E. Cases}

\footnotetext{
${ }^{53}$ See CONLY, supra note.

${ }^{54}$ See UlRich HufFRAGE, Overconfidence, in Cognitive Illusions, supra note, at 235.

${ }^{55}$ See Botti \& Hsee, supra note, at 161.

${ }^{56}$ See CONLY, supra note.
} 
In which cases would it be paternalistic to reject a choice not to choose? Begin with (a) above. ${ }^{57}$ Suppose that people are subjected to criminal punishment if they do not choose (for example to vote or to purchase health care) and that they wish not to choose. To know whether paternalism is involved, we need to identify the reason that people are being forced to choose. If people face some kind of collective action problem, and if coercion is meant to solve that problem, paternalism is not involved. But if public officials believe that it is best for people if they choose, and if they are punishing people in order to ensure that they do what is best for them, then we have a case of paternalism. Everything turns on the reason for the punishment.

Whether or not people should be forced to vote or to purchase health care, there is a plausible argument that in both contexts, the goal of coercion is to solve a collective action problem. But we could easily imagine cases in which people are being forced to choose on the ground that it is good for them to do so, even if they think otherwise. Some of those who support both compulsory voting and the "individual mandate" for health insurance believe exactly that. In the latter context, the idea might be that people suffer from inertia ${ }^{58}$ or fail to make a choice that will protect them in the event that things go unexpectedly wrong.

Now turn to (b), which seems to involve many of the most interesting cases. In those cases, some choosers undoubtedly have a second-order preference not to choose, and active choosing interferes with or overrides that preference. Nonetheless, choice architects are imposing a requirement of active choosing in circumstances in which some or many people, faced with the option, would choose not to choose. Is active choosing paternalistic for that reason?

As before, the answer turns on why choice architects are insisting on active choice. In the case of organ donation, paternalism is not involved. The goal is to protect third parties, not choosers. So too with a case in which a choice architect favors a default rule that reduces environmental harms; in such cases, third parties are at risk. ${ }^{59}$ But suppose that as a condition for entering into an employment relationship, people are asked or required to make an active choice with respect to their heath care plan; suppose too that choice architects believe that it is good for them to do so, even though prospective employees disagree (and would prefer to be defaulted). If so, then choice architects are acting paternalistically. In such cases, those who insist on active choosing are hardly avoiding paternalism; they are engaging in it.

It might seem puzzling to suggest that paternalism might be involved in (c). How can it be paternalistic to say that you do not own a pair of shoes, a tablet, an automobile, or a fish sandwich unless you have actively chosen it? The question is a good one, but it should not be taken as rhetorical; everything depends on the reasons

\footnotetext{
${ }^{57}$ See supra Part II(a).

${ }^{58}$ See Punam Keller et al., Enhanced Active Choice: A New Method to Motivate Behavior Change, 21 J. CONS. PSYCH. 376, 377-78 (2011).

${ }^{59}$ See Sunstein \& Reisch, supra note.
} 
that underlie the creation of a particular system of choice architecture. ${ }^{60}$ To be sure, there are many justifications for free markets and active choosing, and a number of them have nothing to do with paternalism. Some of those justifications speak of efficiency and others of autonomy. But suppose that we think that active choosing is a way to ensure that people develop certain characteristics and tastes. Suppose that the idea is that choosers gain independence, self-sufficiency, and a sense of initiative, and that a system of active choosing (subject to background entitlements) is desirable for exactly that reason. That would be a paternalistic justification, and it might well apply to some choosers in the context of health care.

This view is hardly foreign to those who emphasize the importance of freedom of choice; it plays a significant role in Mill's own defense of liberty. ${ }^{61}$ It is also a cousin of an early defense of free markets, memorably sketched by Albert Hirschmann, which emphasizes that free commerce creates a certain kind of culture, in which traditional social antagonisms, based on religion and ethnicity, are softened as people pursue their economic interests. ${ }^{62}$ For at least some of those who prize active choosing, the concern is not softening of social divisions, but the development of engaged, spirited, informed people. Those who favor active choosing often embrace a form of liberal perfectionism, embodied in the idea that the government legitimately promotes certain desirable characteristics, on the ground that it is best for people to have those characteristics. ${ }^{63}$

To the extent that active choosing promotes independence, self-sufficiency, and a sense of initiative, it might be preferred on perfectionist grounds, even if people would choose not to choose. We might think that this view has strong appeal in the medical context, where it may be desirable for people to exercise agency. One question is whether exercising agency has good, or not-so-good, effects on the prospects for recovery. Perhaps those who favor patient autonomy have ideas of this kind in mind; they are concerned with the value and side-effects of the exercise of agency.

To be sure, it is not exactly standard to see those who embrace free markets or freedom of choice as favoring any kind of paternalism, and it is often wrong to see them in that way, because other justifications are available, and because people often do in fact have a first-order desire to choose, certainly in cases that fall in category (c). ${ }^{64}$ But suppose that private or public institutions favor active choosing, and reject mandates or default rules, because they want to influence people for their own good. Recall our working definition, which suggests that paternalism is involved when a private or public institution does not believe that people's choices will promote their

\footnotetext{
${ }^{60} \mathrm{I}$ am bracketing here the question whether markets can be seen as a kind of spontaneous order, or whether they should be seen as a product of conscious design. For a valuable discussion, see Edna Ullmann-Margalit, Invisible Hand Explanations, 39 SYNTHESE 263 (1978).

${ }^{61}$ See MiLL, supra note.

${ }^{62}$ See Albert Hirschmann, The PASSIONS AND the InTERESTS (1997).

${ }^{63}$ See Joseph Raz, The Morality of FreEdom (1986); liberal perfectionism is criticized by John Rawls, Political Liberalism (1991).

${ }^{64}$ See Ernst Fehr et al., supra note.
} 
welfare, and it is taking steps to influence or alter people's choices for their own good. If people have a second-order desire not to choose, and if active choosing overrides that choice, then paternalism is indeed involved, even in cases that fall in category (c). In the domain of health care, an insistence in active choosing might well be paternalistic - and for some consumers and some patients, it is not justified on grounds of either welfare or autonomy.

\section{Conclusion}

Many people have insisted on an opposition between active choosing and paternalism, and in some cases, they are correct to do so. In the domain of health care, active choosing has an important and permanent place. But in many contexts, the opposition is illusory, even a logical error, because people do not want to choose actively. To be sure, the power to choose may well have intrinsic value, but people often exercise that power by delegating authority to others. Nanny states forbid people from choosing, but they also forbid people from choosing not to choose. ${ }^{65}$ If and to the extent that hospitals and doctor forbid that choice, they are acting as nannies.

If choice architects are prohibiting people from choosing, they might well be acting paternalistically - and the context of health care, paternalism runs into serious objections on the basis of both autonomy and welfare. But if choice architects require people to choose, they may also be acting paternalistically — at least if they are motivated by the belief that active choosing is good and important, notwithstanding the fact that people reject that belief. Insistence on active choosing may simultaneously reduce people's welfare and insult their autonomy - not least when people are vulnerable or aware of their own ignorance, and want some direction and help.

To be sure, active choosing has a central place in a free society, and I have emphasized that it needs to play a large role in the health care system. But for those involved in that system, as for everyone else, the same concerns that motivate objections to paternalism in general can be applied to paternalistic interferences with people's choice not to choose.

\footnotetext{
${ }^{65}$ On their reasons for doing so, see Cass R. Sunstein, Deciding By Default, 162 U. Pa. L. Rev. 1 (2013), and in particular the discussion of learning over time.
} 